\title{
Connect dispatch centers for call handling improves performance
}

\author{
Yann Penverne ${ }^{1}$, Michel Terré ${ }^{2}$, François Javaudin ${ }^{1,3}$, Joël Jenvrin ${ }^{1}$, Frédéric Berthier $^{1}$, Julien Labady ${ }^{1}$, \\ Brice Leclere ${ }^{3,4}$ and Emmanuel Montassier ${ }^{1,3^{*}}$ (i)
}

\begin{abstract}
The aim of this Letter to the Editor was to report a strategy to reduce time waiting for emergency calls in a dispatch center, in line with a recently published article that reviewed evidence for medical dispatching systems to accurately dispatch Emergency medical Services. Here, we tested the effect of a connected distribution of calls, where a call is allocated to the first available resource among a pooled group of telecommunicators from several dispatch centers. We found that connect dispatch centers improve dispatch center performance, especially during an overloaded period. It could be leveraged to handle emergency calls without delay and to appropriately dispatch Emergency Medical Services.
\end{abstract}

Keywords: Emergency medical dispatch, Emergency medical services, Virtualization

To the Editor:

We have read with great interest the article, "The accuracy of medical dispatch - a systematic review" by Bohm and Kurland [1]. The authors reviewed evidence for medical dispatching systems to accurately dispatch Emergency medical Services (EMS), arguing that the challenge is to dispatch EMS appropriately with limited resources. Indeed, dispatch centers receive an increasing number of emergency calls each year, and calls are traditionally routed to the local dispatch center. However, temporal variations of the daily activity emphasize the importance of scheduling process [2-4]. Allocation of additional resources to an activity peak could be a solution. However, impact of such strategy is limited as telecommunicators workforce is constrained and not easily mobilizable for a brief work shift corresponding to the activity peak. To date, collaboration between dispatch centers for call handling process does not exist. Virtual phone system for call distribution consists in distributing calls to connected resources from different geographic locations. Automatic call distribution is achieved through an advanced telephonic system, which dynamically balances the workload

\footnotetext{
* Correspondence: emmanuelmontassier@hotmail.com;

emmanuel.montassier@chu-nantes.fr

${ }^{1}$ Department of Emergency Medicine, SAMU44, CHU Nantes, Nantes, France

${ }^{3}$ MiHAR lab, Université de Nantes, 44000 Nantes, France

Full list of author information is available at the end of the article
}

and allocates calls to available telecommunicator. This operational model enables rapid contact through the pooling of available resources [5]. Thus, the objective of our work was to study the effect of a connected distribution of calls on dispatch center performance.

We compared two models of call distribution: i) monocentric call distribution to call takers of the corresponding geographic area (i.e., calls routed to the local dispatch center) and, ii) virtual phone system distribution to a group of dispatchers physically distributed in several dispatch centers and connected to the same information system, so that the calls are distributed to the resource immediately available in this group. We set the number of dispatchers in each site at five. Based on our previous work, we considered a nominal situation in which the activity observed on a weekday was on average 39 calls per hour, with an average duration of a call of $106 \mathrm{~s}$ [3]. This activity was the basic traffic. We defined the following telephone flows to reflect temporal variation of the activity of the dispatch center: i) Loaded traffic: in busy hours, the traffic is doubled compared to the basic traffic, the average calls per hour is equal to 78 , which leads to a rate of new calls called $\lambda$, equal to $78 / 3600$ calls per second. The traffic is measured in Erlang, a unit of measurement of the telephone traffic that represents the rate of occupation of a resource [6]. A caller who is continuously on call throughout the day would therefore occupy a telephone

(c) The Author(s). 2019 Open Access This article is distributed under the terms of the Creative Commons Attribution 4.0 International License (http://creativecommons.org/licenses/by/4.0/), which permits unrestricted use, distribution, and reproduction in any medium, provided you give appropriate credit to the original author(s) and the source, provide a link to the Creative Commons license, and indicate if changes were made. The Creative Commons Public Domain Dedication waiver (http://creativecommons.org/publicdomain/zero/1.0/) applies to the data made available in this article, unless otherwise stated. 
resource $100 \%$ of the time and thus generate a 1-Erlang traffic. Keeping the average call duration, rated $1 / \mu$, equal to $106 \mathrm{~s}$, we get a traffic $\mathrm{A}=\lambda / \mu$, which gives $\mathrm{A}=2297$ Erlangs; ii) Traffic T75: in periods of high activity, we apply an increase of $75 \%$ of the traffic hours loaded, corresponding to 4019 Erlangs; iii) Traffic T100: in periods of high activity, we also apply a 100\% increase in the traffic hours loaded, corresponding to 4593 Erlangs.

In periods of high activity corresponding to $75 \%$ of the traffic hours loaded, with a monocentric call distribution (i.e., calls routed to the local dispatch center), the probability to be put on hold was $56.2 \%$, with an average waiting time of $61 \mathrm{~s}$. The probabilities of waiting less than $20 \mathrm{~s}$ and $6 \mathrm{~s}$ were 53.3 and $46.9 \%$, respectively. In the virtual phone system model, with a call distribution connecting six dispatch centers, the probability to be put on hold was $18.1 \%$, with an average waiting time of $4 \mathrm{~s}$. The probabilities of waiting less than $20 \mathrm{~s}$ and $6 \mathrm{~s}$ were 94 and $87 \%$, respectively. To achieve the same results with a monocentric call distribution, number of telecommunicators should be increased from 5 to 8 (i.e., $80 \%$ increase). Moreover, when eleven dispatch centers were connected, the probability to be put on hold was $7.9 \%$, with an average waiting time of 1 $\mathrm{s}$. In this case, the probabilities of waiting less than $20 \mathrm{~s}$ and $6 \mathrm{~s}$ were 99 and $95.7 \%$, respectively. We also tested our model in periods of high activity corresponding to $100 \%$ of the traffic hours loaded. With a monocentric call distribution model, the probability to be put on hold was $80.5 \%$, with an average waiting time of $210 \mathrm{~s}$. The probabilities of waiting less than $20 \mathrm{~s}$ and $6 \mathrm{~s}$ were 25.5 and $21.4 \%$, respectively. In the virtual phone system model, with a call distribution including twenty dispatch centers, the probability to be put on hold was $30.4 \%$, with an average waiting time of $4 \mathrm{~s}$. The probabilities of waiting less than $20 \mathrm{~s}$ and $6 \mathrm{~s}$ were 93 and 81\% respectively. To achieve the same results with a monocentric call distribution, number of telecommunicators should be increased from 5 to 9 (i.e., $90 \%$ increase).

Here, we found that connecting dispatch centers can help to improve time waiting for emergency calls. Our results support that dispatch center virtualization could be applied in case of activity peak, by determining the available telecommunicator in a large panel of call takers connected from different geographic locations. Thus, virtual phone system for call distribution can improve dispatch center accessibility, especially during an overloaded period. It could be leveraged to handle emergency calls without delay. Programs of dispatch center modernization should discuss the implementation of such model of call distribution. Collaborative projects between dispatch centers should be created to promote rapid access to a telecommunicator, to evaluate whether emergency medical services are needed and with which priority the resource needs to be dispatched [7].
Abbreviation

EMS: emergency medical services

Acknowledgements

Not applicable.

Funding

No funding received for this work.

Availability of data and materials

Please contact author for data requests.

Authors' contributions

$Y P, F B, J L$, and MT conceived the study. YP, MT, JJ, JL, and BL developed the analysis plan, and MT undertook the main analysis with supervision from YP and BL. EM and FJ wrote the first draft of the paper, with all other authors making important critical revisions. All authors have read and approved the final version of the manuscript.

Ethics approval and consent to participate

Not applicable.

Consent for publication

Not applicable.

Competing interests

The authors declare that they have no competing interests.

\section{Publisher's Note}

Springer Nature remains neutral with regard to jurisdictional claims in published maps and institutional affiliations.

\section{Author details}

'Department of Emergency Medicine, SAMU44, CHU Nantes, Nantes, France. ${ }^{2}$ Conservatoire National des Arts et Métiers CEDRIC, 292 rue Saint Martin, 75003 Paris, France. ${ }^{3}$ MiHAR lab, Université de Nantes, 44000 Nantes, France. ${ }^{4}$ Department of Medical Evaluation and Epidemiology, Nantes University Hospital, 85, rue St Jacques, 44093 Nantes Cedex 1, France.

Received: 26 January 2019 Accepted: 10 February 2019

Published online: 20 February 2019

\section{References}

1. Bohm K, Kurland K. The accuracy of medical dispatch - a systematic review. Scandinavian Journal of Trauma, Resuscitation and Emergency Medicine. 2018;26:94.

2. Cantwell K, Morgans A, Smith K, Livingston M, Spelman T, Dietze P. Time of day and day of week trends in EMS demand. Prehosp Emerg Care. 2015:19:425-31.

3. Penverne $Y$, Leclere B, Labady J, Berthier F, Jenvrin J, Javaudin F, et al. Key performance indicators' assessment to develop best practices in an emergency medical communication Centre. Eur J Emerg Med. 2017;25:335-40.

4. Sariyer G. Sizing capacity levels in emergency medical services dispatch centers: using the newsvendor approach. Am J Emerg Med. 2018;36:804-15.

5. Aksin Z, Armony M, Mehrotram V. The modern call-center: a multidisciplinary perspective on operations management research. Prod Oper Manag. 2007;16:665-88.

6. Daoud YM. Foundations of Mobile Radiocommunications. New York: CRC Press; 1993.

7. Snooks H, Evans A, Wells B, Peconi J, Thomas M, Woolard M, et al. What are the highest priorities for research in emergency prehospital care? Emerg Med J. 2009;26:549-50. 